\title{
COVID-19 Pandemic: Oral Repercussions and its Possible Impact on Oral Health
}

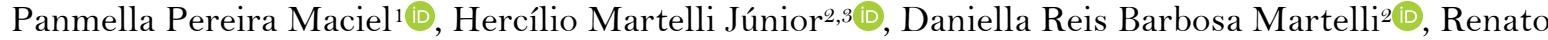 \\ Assis Machado ${ }^{4,5}$ (), Priscila Victor de Andrade ${ }^{6}$, Danyel Elias da Cruz Perez ${ }^{7}$, Paulo Rogério \\ Ferreti Bonan 1 (1)
}

\begin{abstract}
${ }^{1}$ Department of Clinical and Social Dentistry, School of Dentistry, Federal University of Paraiba, João Pessoa, PB, Brazil. 2Oral Diagnosis, School of Dentistry, State University of Montes Claros, Montes Claros, MG, Brazil.

${ }^{3}$ Center for Rehabilitation of Craniofacial Anomalies, School of Dentistry, Unifenas, MG, Brazil.

${ }^{4}$ Department of Oral Diagnosis, School of Dentistry, University of Campinas, Piracicaba, SP, Brazil.

${ }^{5}$ Hospital for Rehabilitation of Craniofacial Anomalies, University of São Paulo, Bauru, SP, Brazil.

${ }^{6}$ Medicine School, State University of Montes Claros, Montes Claros, MG, Brazil.

${ }^{7}$ Department of Clinical and Preventive Dentistry, School of Dentistry, Federal University of Pernambuco, Recife, PE, Brazil.
\end{abstract}

Author to whom correspondence should be addressed: Panmella Pereira Maciel, Rua José Simões de Araújo, 611, Bessa, João Pessoa, PB, Brazil. 58035-070. Phone: +55 83 981240358. E-mail: panmellamaciel@hotmail.com.

Academic Editor: Yuri Wanderley Cavalcanti

Received: 18 June 2020 / Accepted: 27 June 2020 / Published: 13 July 2020

How to cite this article: Maciel PP, Martelli Júnior H, Martelli DRB, Machado RA, Andrade PV, Perez DEC, et al. COVID-19 pandemic: oral repercussions and its possible impact on oral health. Pesqui Bras Odontopediatria Clín Integr. 2020; 2O(supp1):e0138. https://doi.org/10.1590/pboci.2020.135

\begin{abstract}
Many viral infections cause oral manifestations, including disorders in odontogenesis, resulting in dental malformations. In this review, based on current knowledge, we will discuss the likely dental and oral consequences of COVID-19. In this article, we review currently available data associated with vertical transmission of COVID-19 and odontogenesis, oral manifestations, and the impact of COVID-19 pandemic on a diagnosis of oral diseases. Owing to the severity of the pandemic, the population's anxiety and fear of becoming infected with COVID-19 may underestimate the signs and symptoms of serious illnesses, besides discourage patients from seeking health, medical or dental services to determine the diagnosis of oral lesions. Thus, the COVID-19 pandemic could be an additional and aggravating factor for the delay of serious illness diagnosis, such as oral squamous cell carcinoma resulting in higher morbidity and worse prognosis. Several changes and oral lesions have been described as oral manifestations of COVID-19, such as dysgeusia, oral ulcers, petechiae, reddish macules, desquamative gingivitis, among others. Besides, it can cause major systemic changes and predispose opportunistic infections. As with other viral infections, oral manifestations, including dental anomalies, can occur as a direct result of SARS-CoV-2 infection. However, further studies are needed to guide and clarify possible oral changes.
\end{abstract}

Keywords: Coronavirus, Odontogenesis, Tooth Abnormalities, Infectious Disease Transmission, Vertical. 


\section{Introduction}

In December 2019, a novel coronavirus (SARS-CoV-2), which causes COVID-19, has spread from Wuhan (China) to other countries, triggering an unprecedent global crisis. On March 11, 2020, the World Health Organization (WHO) declared the COVID-19 outbreak as a pandemic. Globally, as the June 16, 2020, there were more than 7,9 million confirmed cases of COVID-19, and 434,796 deaths, in more than 200 countries. Brazil represents the second most affected country, with more than 900,000 confirmed cases, with 43,332 deaths [1]. The main symptoms are headache, fever, cough, sore throat, tiredness, dyspnea, and enteritis (diarrhea). The most worrying consequence of disease is severe acute respiratory syndrome (SARS), besides the increased risk of venous thromboembolism, which may result in higher risk of complications [2,3].

Isolation and social distancing measures have been implemented worldwide to contain the accelerated spread of COVID-19. Among the consequences, dental clinics, both public and private, importantly in oral diagnosis, were temporarily closed, with elective dental care suspended [4]. In addition, dental school clinics were closed due to the interruption of the classroom and clinical teaching activities. Particularly in Brazil, most of the oral diagnosis units are in dental schools. Therefore, most of them continue with suspended face-to-face consultations.

Regarding oral health, many viral infections cause oral manifestations, including disorders in odontogenesis, resulting in dental malformations. Considering the current knowledge about the pathogenesis and biological behavior of COVID-19, is it possible to consider oral manifestations as a direct consequence of SARS-CoV-2 infection? Moreover, with the interruption of oral diagnostic services, what is the impact on the diagnosis of oral diseases? In this review, based on current knowledge, we will discuss the likely dental and oral consequences of COVID-19.

\section{COVID-19 and Defects in Odontogenesis: Is There a Biological Basis for Increased Risk of}

\section{Dental Anomalies?}

Studies have been published on vertical transmission of SARS-CoV-2 and the risk in the general health of newborns but few data on the effect of SARS-CoV-2 in pregnancy are available. These studies seem to be reassuring that pregnant women with SARS-CoV-2 disease (COVID-19) might not be at increased risk for severe complications or adverse reproductive health outcomes, but the reports have also been conflicting and inconclusive as to whether vertical transmission of SARS-CoV-2 and the possible congenital alterations that can occur $[5,6]$.

Dental anomalies can be caused by viral diseases transmitted from mother to child during pregnancy. Dental anomalies reflect specific disturbances of one or more stages of odontogenesis, roughly classified as tooth initiation, morphogenesis, cytodifferentiation, mineralization, and bone modeling occurring with eruption [7]. During these processes, viral infections can interrupt dental formation or morphogenesis as do well-known viruses, such as varicella-zoster, parvovirus B-19, herpes infections, rubella, cytomegalovirus and Zika virus [8]. Considering Zika virus as an example, dental shape, chronology and sequence of eruption are evidently altered [9]. These infections have caused changes in the tooth number, shape, size, structure, and/or position, in addition to delayed or absent tooth eruption. Due to the uncertainties and the absence of studies involving vertical transmission of the SARS-CoV-2 and COVID-19, this text suggests reflections and future studies for the monitoring of possible dental anomalies in children, both in the deciduous and permanent dentition. The possible dental alterations associated with this scenario are Hypodontia, Gyroversion, Microdontia, Enamel Hypoplasia, Enamel Hipomineralization, Impacted teeth, Shovel-shaped teeth, Dens in 
dens, Dens invaginatus and Dens evaginatus, Taurodontism and Ghost teeth. Some of these changes are illustrated in Figure 1.

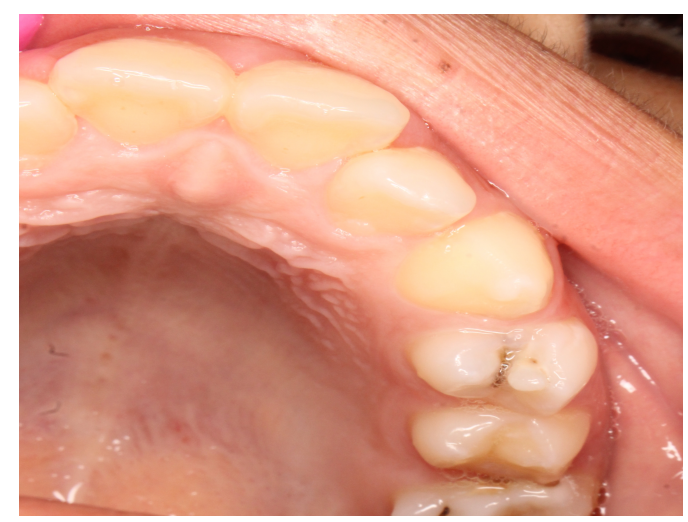

Figure 1. Shovel-shaped incisors and dens evaginatus.

\section{Oral Manifestations of COVID-19. What is the Evidence?}

Simultaneous gustatory and olfactory disorders without concomitant nasal congestion have been reported by most patients, mainly those with mild symptomatic forms [10]. The angiotensin-converting enzyme 2 (ACE2) receptor, which the SARS-CoV-2 binds to infect the host cells, is highly expressed in the epithelial cells of the tongue [11]. Based on this finding, dysgeusia could be considered the first oral manifestation as a direct consequence of SARS-CoV-2 infection [12]. However, some questions should be discussed to consider this hypothesis. Most gustatory disorders are caused by dysfunctions of olfactory system. Thus, in these patients, an olfactory disorder must be studied as the primary cause of taste disorder [13]. In addition, hyposalivation or changes in saliva composition, can induce dysgeusia/ageusia. A recent study revealed that more than 50\% of COVID-19 patients presented xerostomia and dysgeusia, with significant correlation between these two symptoms [14]. On the other hand, taste is recognized as the main stimulant for salivary secretion. Therefore, further studies are needed to determine whether taste dysfunction is a direct consequence of SARS-CoV-2 infection.

Several single cases or short case series of oral manifestations of COVID-19 have been reported. At the same time, questions have been raised to discuss whether these lesions are a consequence of direct infection of SARS-CoV-2 or are secondary manifestations of COVID-19. Oral ulcers, petechiae and reddish macules, mainly in palate [15], besides desquamative gingivitis, and blisters in lower lip and buccal mucosa have been described. It is important to highlight that the acute condition caused by COVID-19 may predispose to other opportunistic infections, such as herpes simplex, candidiasis [16], which may have a similar clinical appearance. Since there is no standard treatment for COVID-19, many different drugs are administered to patients, especially those who experience respiratory complications. In addition to medications that can cause oral side effects, the length of hospital stay, with the possible need for orotracheal intubation, can also produce changes in the oral mucosa [16]. We should also consider other endemic infectious diseases, especially in developing countries like Brazil, which may have similar oral lesions [17]. In some reported cases, SARS-CoV2 infection has not been confirmed [18]. Therefore, further investigations and a careful review of the cases reported in the literature are important to determine the origin of such oral lesions.

In addition, COVID-19 causes major systemic changes, especially extensive inflammatory state due to cytokine storm and increased risk of venous thromboembolism. The multisystem inflammatory syndrome has 
been described in children positive for SARS-CoV-2 antibodies. The children present a hyperinflammatory shock, characterized by fever, shock, cutaneous rash, gastroenteritis, conjunctivitis, and edema in the extremities. The patients may also present fissured lips and strawberry tongue [19]. In these cases, the oral manifestations are secondary to underlying systemic disorders.

\section{Impact of COVID-19 Pandemic on Diagnosis of Oral Diseases}

Despite the interruption of elective dental care, chronic diseases with a significant clinical impact continue to occur. Various diseases, with distinct clinical significance, from inflammatory/reactive to neoplastic, can occur in the mouth. Oral squamous cell carcinoma (OSCC) is the disease of highest clinical significance. In 2018, data from GLOBOCAN estimated that there were 354,900 new cases of OSCC worldwide, with 177,400 deaths caused by the disease [20]. In Brazil, the National Cancer Institute estimates the occurrence of 15,000 new cases of OSCC in the 2020-2021 biennium [21]. GLOBOCAN data reveal that Brazil has the fifth highest prevalence of OSCC in the world [20]. Delay in diagnosis is common in OSCC patients. Thus, most cases are diagnosed at an advanced clinical stage, resulting in high rates of morbidity and mortality [22].

Generally, the population relates dental emergencies only to odontogenic pain, such as irreversible pulpitis and acute dentoalveolar abscesses. Owing to the severity of the pandemic, the population's anxiety and fear of becoming infected with COVID-19 may underestimate the signs and symptoms of other serious illnesses. In the same way, this context may also discourage patients from seeking health, medical or dental services to investigate the origin and determine the diagnosis of oral lesions. Thus, COVID-19 pandemic could be an additional and aggravating factor for the delay of OSCC diagnosis, resulting in higher morbidity and worse prognosis. A preliminary report from an oral diagnosis center in the Metropolitan Region of Turin, Italy, one of the regions most affected by the pandemic, identified a significant decrease in the number of OSCC diagnosed during the pandemic [23]. In Brazil, the scenario can be even worse, because most of the oral diagnostic units are closed. A study evaluating the natural history of untreated head and neck cancer showed that the mean survival was 4 months, and only $11 \%$ of the patients survive more than one year [24].

Other serious diseases with oral manifestations, such as other malignant neoplasms, immunologically mediated diseases, such as pemphigus, lupus, pemphigoid, are likely to be underdiagnosed or undiagnosed during the pandemic [25]. To minimize this impact, we recently highlighted the importance of social media and teledentistry for oral diagnosis during the pandemic period, especially in lesions suspected of malignancy [24].

\section{Conclusion}

Several changes and oral lesions have been described as oral manifestations of COVID-19. As with other viral infections, oral manifestations, including dental anomalies, can occur as a direct result of SARSCoV-2 infection. However, we must analyze the changes associated with COVID-19 reported in the literature with caution, aware that further studies are needed to clarify whether these oral changes are really possible.

\section{Authors' Contributions}

\footnotetext{
PPM (D) 0000-0003-0168-5833 Writing-Original Draft Preparation and Writing - Review and Editing.

HMJ (D) 0000-0001-9691-2802 Conceptualization, Investigation, Writing - Original Draft Preparation and Writing - Review and Editing.
} 
DRBM (D) 0000-0002-7497-6052 Conceptualization, Investigation, Writing - Original Draft Preparation and Writing - Review and Editing.

RAM (D) 0000-0002-1697-3662 Conceptualization, Investigation and Writing - Review and Editing.

PVA (D) 0000-0003-0014-6096 Conceptualization, Investigation and Writing - Review and Editing.

DECP (D) 0000-0002-4591-4645 Conceptualization, Investigation and Writing - Review and Editing.

PRFB (D) 0000-0002-4449-4343 Conceptualization, Investigation and Writing-Review and Editing.

All authors declare that they contributed to critical review of intellectual content and approval of the final version to be published.

\section{Financial Support}

None.

\section{Conflict of Interest}

The authors declare no conflicts of interest.

\section{References}

[1] World Health Organization. WHO Coronavirus Disease (COVID-19) Dashboard. Available from: https://who.sprinklr.com. [Accessed on June 16, 2020].

[2] Hendren NS, Drazner MH, Bozkurt B, Cooper LT Jr. Description and proposed management of the acute COVID-19 cardiovascular syndrome. Circulation 2020; 141:1903-14. https://doi.org/10.1161/CIRCULATIONAHA.120.047349

[3] Aryal MR, Gosain R, Donato A, Pathak R, Bhatt VR, Katel A, et al. Venous thromboembolism in COVID-19: towards an ideal approach to thromboprophylaxis, screening, and treatment. Curr Cardiol Rep 2020; $22(7): 52$. https://doi.org/10.1007/s11886-020-01327-9

[4] Perez DEC, Passos KKM, Machado RA, Martelli-Junior H, Bonan PRF. Continuing education in oral cancer during coronavirus disease $2019 \quad$ (covid-19) outbreak. Oral Oncol 2020; 105:104713. https://doi.org/10.1016/j.oraloncology.2020.104713

[5] Gatta AND, Rizzo R, Pilu G, Simonazzi G. COVID19 during pregnancy: a systematic review of reported cases. Am J Obstet Gynecol 2020; So002-9378(20)30438-5. https://doi.org/10.1016/j.ajog.2020.04.013

[6] Dong L, Tian J, He S, Zhu C, Wang J, Liu C, et al. Possible vertical transmission of SARS-CoV-2 from an infected mother to her newborn. JAMA 2020; 323(18):1846-8. https://doi.org/10.1001/jama.2020.462 1

[7] Thesleff I, Tummers M. Tooth organogenesis and regeneration. StemBook. Cambridge (MA): Harvard Stem Cell Institute; 2009. https://doi.org/10.3824/stembook.1.37.1

[8] Silva MCPMD, Arnaud MA, Lyra MCA, Alencar Filho AV, Rocha MÂW, Ramos RCF, et al. Dental development in children born to Zikv-infected mothers: a case-based study. Arch Oral Biol 2020; 110:104598. https://doi.org/10.1016/j.archoralbio.2019.104598

[9] Carvalho IF, Alencar PNB, Andrade MDC, Silva PGB, Carvalho EDF, Araújo LS, et al. Clinical and x-ray oral evaluation in patients with congenital Zika Virus. J Appl Oral Sci 2019; 27:e20180276. https://doi.org/10.1590/1678-7757-2018-0276

[10] Chary E, Carsuzaa F, Trijolet JP, Capitaine AL, Roncato-Sabera M, Fouet K, et al. Prevalence and recovery from olfactory and gustatory dysfunctions in Covid-19 infection: a prospective multicenter study. Am J Rhinol Allergy 2020; 1945892420930954. https://doi.org/10.1177/1945892420930954

[11] Xu H, Zhong L, Deng J, Peng J, Dan H, Zeng X, et al. High expression of ACE2 receptor of 2019-nCoV on the epithelial cells of oral mucosa. Int J Oral Sci 2020; 12(1):8. https://doi.org/10.1038/s41368-020-0074-X

[12] Mariz BALA, Brandão TB, Ribeiro ACP, Lopes MA, Santos-Silva AR. New insights for the pathogenesis of COVID19-related dysgeusia. J Dent Res 2020; 2020:22034520936638. https://doi.org/10.1177/0022034520936638

[13] Vinayachandran D, Balasubramanian S. Is gustatory impairment the first report of an oral manifestation in COVID19? Oral Dis 2020; 10.1111/odi.13371. https://doi.org/10.1111/odi.13371

[14] Biadsee A, Biadsee A, Kassem F, Dagan O, Masarwa S, Ormianer Z. Olfactory and oral manifestations of COVID-19: sex-related symptoms - a potential pathway to early diagnosis. Otolaryngol Head Neck Surg 2020; 194599820934380 https://doi.org/10.1007/s00405-020-05965-1

[15] Soares CD, Carvalho RA, Carvalho KA, Carvalho MG, Almeida OP. Oral lesions in a patient with Covid-19. Med Oral Patol Oral Cir Bucal 2020; 2020:24044. https://doi.org/10.4317/medoral.24044

[16] Santos JAD, Normando AGC, Silva RLCD, Paula RM, Cembranel AC, Santos-Silva AR, et al. Oral mucosal lesions in a COVID-19 patient: new signs or secondary manifestations? Int $J$ Infect Dis 2020; 97:326-8. https://doi.org/10.1016/j.ijid.2020.06.012 
[17] Rocha BA, Souto GR, Grossmann SMC, Aguiar MCF, Andrade BAB, Romañach MJ, Horta MCR. Viral enanthema in oral mucosa: a possible diagnostic challenge in the COVID-19 pandemic. Oral Dis 2020; 10.1111/odi.13473. https://doi.org/10.1111/odi.13473

[18] Carreras-Presas CM, Sánchez JA, López-Sánchez AF, Jané-Salas E, Pérez MLS. Oral vesiculobullous lesions associated with SARS-CoV-2 infection. Oral Dis 2020; 10.1111/odi.13382. https://doi.org/10.1111/odi.13382

[19] Chiotos K, Bassiri H, Behrens EM, Blatz AM, Chang J, Diorio C, et al. Multisystem inflammatory syndrome in children during the COVID-19 pandemic: a case series. J Pediatric Infect Dis Soc. 2020; piaa069. https://doi.org/10.1093/jpids/piaa069

[20] Ferlay J, Colombet M, Soerjomataram I, Mathers C, Parkin DM, Piñeros M, et al. Estimating the global cancer incidence and mortality in 2018: GLOBOCAN sources and methods. Int J Cancer 2019; 144:1941-53. https://doi.org/10.1002/ijc.31937

[21] Instituto Nacional de Câncer. Estimativa 2020: incidência de câncer no Brasil. Available from: https://www.inca.gov.br/sites/ufu.sti.inca.local/files//media/document//estimativa-2020-incidencia-de-cancer-nobrasil.pdf. [Accessed on June 17, 2020]. [In Portuguese]

[22] Güneri P, Epstein JB. Late stage diagnosis of oral cancer: components and possible solutions. Oral Oncol 2014; 50:1131-6. https://doi.org/10.1016/j.oraloncology. 2014.09.005

[23] Arduino PG, Conrotto D, Broccoletti R. The outbreak of Novel Coronavirus disease (COVID-19) caused a worrying delay in the diagnosis of oral cancer in north-west Italy: the Turin Metropolitan area experience. Oral Dis 2020; 10.1111/odi.13362. https://doi.org/10.1111/odi.13362

[24] Kowalski LP, Carvalho AL. Natural history of untreated head and neck cancer. Eur J Cancer 2000; 36(8):1032-7. https://doi.org/10.1016/s0959-8049(00)00054-x

[25] Machado RA, de Souza NL, Oliveira RM, Martelli Júnior H, Bonan PRF. Social media and telemedicine for oral diagnosis and counselling in the COVID-19 era. Oral Oncol 2020; 105:104685. https://doi.org/10.1016/j.oraloncology.2020.104685 